\title{
Virtual Reality at the Service of People with Functional Diversity: Personalized Intervention Spaces ${ }^{\dagger}$
}

\author{
Manuel Lagos*D, Jessica Martín, Ángel Gómez (D) and Thais Pousada (D) \\ CITIC (Centre for Information and Communications Technology Research), Elviña Campus, \\ University of A Coruña, 15071 A Coruña, Spain; j.martin1@udc.es (J.M.); angel.gomez@udc.es (Á.G.); \\ thais.pousada.garcia@udc.es (T.P.) \\ * Correspondence: m.lagos@udc.es \\ + Presented at the 4th XoveTIC Conference, A Coruña, Spain, 7-8 October 2021.
}

check for updates

Citation: Lagos, M.; Martín, J.;

Gómez, Á.; Pousada, T. Virtual Reality at the Service of People with Functional Diversity: Personalized Intervention Spaces. Eng. Proc. 2021, 7, 43. https://doi.org/10.3390/ engproc2021007043

Academic Editors: Joaquim de Moura, Marco A. González, Javier Pereira and Manuel G. Penedo

Published: 20 October 2021

Publisher's Note: MDPI stays neutral with regard to jurisdictional claims in published maps and institutional affiliations.

Copyright: (c) 2021 by the authors. Licensee MDPI, Basel, Switzerland. This article is an open access article distributed under the terms and conditions of the Creative Commons Attribution (CC BY) license (https:// creativecommons.org/licenses/by/ $4.0 /)$.

\begin{abstract}
Virtual reality allows to generate an environment of great realism, while achieving the immersion of the user in it. The purpose of this project is to use this technology as a complementary tool in the rehabilitation of people with functional diversity. To do this, an application is being developed that will offer different environments that simulate situations in everyday life. Through its initial menu, the professional will be able to select the virtual work environment, with different configuration options to adapt each scenario to the user's needs. This customization of the scenarios will allow such things as configuring the degree of difficulty of the activity to eventually adapting the elements of the scenario to the functional capacity of the user.
\end{abstract}

Keywords: virtual reality; immersive environment; functional diversity; unity; leap motion

\section{Introduction}

The rehabilitation process of people with functional diversity is complex, and during the sessions carried out by health professionals, different elements are used to configure an appropriate environment to deal with the user's difficulties. For the configuration of these environments (in a controlled way), the presence of possible physical or economic limitations is frequent. Physical, in terms of the characteristics of the space in which the sessions are held, and the difficulty of replicating different environments, especially outdoors, so that the person can put their daily life skills into practice; and economic, in terms of the outlay to be made in the acquisition of various materials, which could be used to configure the different environments.

Virtual reality is a technological resource that allows to generate spaces of great realism, while achieving the immersion of the user in them. So why not harness the potential of virtual reality in the rehabilitation of people with functional diversity?

The use of this technology makes it possible to considerably reduce the physical limitations mentioned above. Thus, custom environments can be programmed, adding any element through 3D modeling.

Therefore, the objective of this project was to use virtual reality as a complementary means of intervention in rehabilitation sessions with people with functional diversity. To achieve this objective, an application is being developed that will offer different environments that simulate everyday life situations.

\section{Technologies}

As for the technologies used, a virtual reality equipment HTC VIVE [1] is used, which will be in charge of creating the virtual reality experience, allowing the user to be immersed in the different scenarios developed.

It is worth highlighting the use of the Leap Motion [2] device, an optical system capable of tracking the movement of the person's hands and fingers, which allows her/him 
to interact with the different environments directly, without the need for controls. The incorporation of this device was an added value in the project since, precisely, several work environments are intended to work mobility problems in the hands, which is undoubtedly carried out more effectively by avoiding the use of controls as a means of interaction with this virtual space.

Unity [3], a real-time development platform, is used as the programming environment, allowing the creation of interactive environments for multiple platforms, such as PCs, consoles, or virtual reality equipment.

\section{Description of the Application}

Through the main menu, the professional will be able to select the virtual work environment and its characteristics, with different configuration options to adapt each scenario to the user's needs (both physically and cognitively).

Work environments are modeled in the form of a test, with a series of objectives that the user must achieve. In this way, it is intended that the person who runs the test feels motivated to achieve the established goals, while training and progressively improving their abilities, reducing their functional limitations.

One of the scenarios under development represents a vegetable garden with different vegetables that the user must collect. This scenario can be configured to train both physical and cognitive abilities. Likewise, the level of difficulty of the activity can also be chosen, allowing the training to be adapted according to the user's progress.

In terms of physical work, the application was intended to strengthen the abdominal musculature in people using wheelchairs. To do this, one of the tasks proposed to the user was to collect tomatoes and place them in different boxes. The height of the plants can be configured in the main menu, allowing to adapt the level of difficulty to the user's abilities, as indicated above.

If the goal is to work cognitive skills, the garden will not only contain tomatoes, but a multitude of vegetables. In this case, the objective to be achieved by the user will be to complete several boxes with different combinations of vegetables.

Another of the environments being developed simulates a supermarket. This scenario is of great interest due to the number of daily life tasks that it allows us to train. Some of the activities that are under development are: Purchase of a series of items indicated in a list, selection of the products necessary to prepare a cooking recipe, or cash payment training.

All these developments are in progress, and the research team is working with professionals and persons with functional diversity to get their opinion about different features during the application of virtual scenarios. Several work meetings have been carried out to get the perspectives of future users.

\section{Discussion}

Currently, there are different digital distribution platforms for video games that include virtual reality applications in their catalog, such as Steam [4].

When using commercial applications as a complementary tool in rehabilitation sessions with people with functional diversity, it is possible to find several drawbacks, such as the lack of customization, since they are general-purpose applications with few configuration options. It is also common to find very complex applications, with unclear instructions and no feedback to guide the user during the game [5]. Generally, controllers are used as a means of interaction, which is a drawback for people with a functional limitation in their hands.

In a review about the application of Virtual Reality in Complex Medical Rehabilitation, authors once analyzed the literature and concluded that the use of virtual environments has proven effectiveness on the recovery of impaired motor skills in people with disabilities. However, to get the optimal results of this application, a personalized approach and monitoring registration of some physical and cognitive variables are required [6]. 
Therefore, the application being developed in this project is a great contribution to the use of virtual reality in the rehabilitation of people with functional diversity, allowing the adaptation of the environments to the user's needs, offering visual and auditory feedback during the execution of the game and allowing to dispense with controls, thanks to the use of the Leap Motion device.

\section{Conclusions}

The application presented here is a novelty development to be applicated in the field of health, concretely, in the rehabilitation's intervention with people with functional diversity. The use of virtual environments, personalized to the skills of the user by rehabilitation, professionally constitutes a motivating factor to enhance him/her to actively participate and compromise in her/his progression of the treatment.

The customized virtual environments developed in the present project have clear advantages:

- The virtual reality itself supposes a potent technological tool in the rehabilitation process, offering multiple possibilities to bring a great variety of scenarios into the room of the intervention center or hospital.

- The possibility of customizing the levels of both physical and cognitive tasks presented in each scenario allows to establish specific goals and activities for each person, and to adjust them according the improvement of the user.

- The use of Leap Motion combined with the virtual reality glasses offers a greater immersive experience, avoiding the need for controls, and allowing the person to use her/his hands and fingers to improve their coordination and dexterity skills themselves.

In the future, we expect that this application will be a consistent tool showing different and motivating scenarios of daily life which has been implemented, at low cost, in rehabilitation centers.

Author Contributions: Conceptualization, Á.G. and M.L.; methodology, M.L. and T.P.; software, M.L. and Á.G.; validation, M.L.; T.P. and J.M.; formal analysis, Á.G.; investigation, M.L.; resources, T.P.; data curation, J.M.; writing—original draft preparation, M.L. and J.M.; writing—review and editing, T.P. and Á.G.; visualization, J.M.; supervision, Á.G.; project administration, Á.G. and T.P.; funding acquisition, T.P. All authors have read and agreed to the published version of the manuscript.

Funding: This research had the support for its publication by National Program of R+D+i oriented to the Challenges of Society 2019 (coordinated research) Grant number: PID2019-104323RB-C33. Ministry of science and innovation.

Institutional Review Board Statement: Not applicable.

Informed Consent Statement: Not applicable.

Data Availability Statement: Not applicable.

Acknowledgments: The development of the project is supported by CITIC as a Research Center of the Galician University System is financed by the Consellería de Educación, Universidades y Formación Profesional (Xunta de Galicia) through the ERDF (80\%), Operational Program ERDF Galicia 2014-2020 and the remaining 20\% by the Secretaria Xeral de Universidades (Ref. ED431G 2019/01).

Conflicts of Interest: The authors declare no conflict of interest.

\section{References}

1. HTC VIVE. Available online: https://www.vive.com/eu/product/vive/ (accessed on 23 July 2021).

2. Leap Motion. Available online: https:/ /www.ultraleap.com/product/leap-motion-controller/ (accessed on 10 June 2021).

3. Unity. Available online: https://unity.com/es (accessed on 20 July 2021).

4. Steam. Available online: https://store.steampowered.com (accessed on 28 July 2021). 
5. Miranda-Duro, M.d.C.; Concheiro-Moscoso, P.; Viqueira, J.L.; Nieto-Riveiro, L.; Domínguez, N.C.; García, T.P. Virtual Reality Game Analysis for People with Functional Diversity: An Inclusive Perspective. Proceedings 2020, 54, 20. [CrossRef]

6. Volovik, M.G.; Borzikov, V.V.; Kuznetsov, A.; Bazarov, D.; Polyakova, A.G. Virtual Reality Technology in Complex Medical Rehabilitation of Patients with Disabilities. Review. Sovrem. Tehnol. Med. 2018, 10, 173. [CrossRef] 